\title{
Sensing of typical gaseous malodors in organic decomposition products
}

\author{
B. Fabbri ${ }^{1}$, A. Giberti ${ }^{1,2}$, V. Guidi ${ }^{1,2,3}$, C. Malagú ${ }^{1,3}$ \\ ${ }^{1}$ Department of Physics, University of Ferrara, Via Saragat 1/c, 44122 Ferrara, Italy, \\ ${ }^{2}$ MIST E-R S.C.R.L., Via P. Gobetti 101, 40129 Bologna, Italy \\ ${ }^{3}$ IDASC - Istituto di Acustica e Sensoristica "O. M. Corbino," Italy \\ guidi@fe.infn.it
}

\begin{abstract}
We approached the problem of sensing gaseous pollutants and malodors originated as a result of decomposition of organic compounds via chemoresistive sensors. A set of four sensors based on screen-printed films of mixed tin and titanium oxides, mixed tungsten and tin oxides, and zinc oxide has been tested vs. the main gaseous components of these malodors. N-butanol was also considered because of its importance as a reference gas in the odorimetric intensity scale. We found that, under proper working conditions, the films can sensitively detect such gases either in dry or in wet environments, within the range of concentrations of interest for monitoring.
\end{abstract}

Key words: gas sensor, odors, sensor array, solid solutions

\section{Introduction}

Within certain contexts there is need to control the concentration of gases that result from decomposition of organic compounds. Pollutants and malodors often accompany decomposition processes, giving rise to serious risks and/or discomfort to the human agglomerates neighboring the plants where such gases are generated. Among all wide variety of decomposition gases we targeted ammonia, ethyl-mercaptan and sulphydric acid, because they are tracers of decomposition with stinging odor to our nose, down to very low concentrations. In the odorimetric intensity scale, n-butanol is a reference gas, which is used to fix the threshold for the human perception of an odor. For this reason, in this work we tested the sensors also vs. this gas. The range of applications spans rather widely over monitoring in green-agriculture fertilization, livestock holdings with the decomposition process of manure, landfills, food-quality, emissions of chemical industries.

Chemoresistive gas sensors based on metal oxides are extremely sensitive devices, appreciated for their low-cost, compactness and full compatibility with standard electronics. In this work, we addressed the problem of detecting decomposition malodors by means of gas sensors based on thick-films of four oxides and mixed solid solutions of oxides. The response at various temperatures vs. concentrations values in the range of interest to identify the best detecting temperature for each type of sensing material vs. the different gases will be shown.

\section{Experimental}

A set of four metal oxide semiconducting films has been selected for the purpose. The materials chosen are $\mathrm{ZnO}$, two solid solutions of $\mathrm{SnO}_{2}$ and $\mathrm{TiO}_{2}$, in proportions of $30 \%-70 \%$ respectively (named ST30), and 90\% - 10\% respectively (named ST90), and a solid solution of $\mathrm{WO}_{3}$ and $\mathrm{SnO}_{2}$ in proportions of $30 \%-70 \%$ respectively (named WS30).

$\mathrm{ZnO}$ powders were prepared dissolving a proper amount of $\mathrm{Zn}\left(\mathrm{NO}_{3}\right)_{2} \cdot 4 \mathrm{H} 2 \mathrm{O}$ in doubly distilled water [1]. The reaction mixture was stirred for $1 \mathrm{~h}$ and kept at room temperature for $24 \mathrm{~h}$, then the product was washed, filtered and dried at $80^{\circ} \mathrm{C}$, and finally calcined at $450 \circ \mathrm{C}$ for 2 h. WS30 is a solid solution of $W$ and $S n$ oxides (with $\mathrm{Sn}: \mathrm{W}=30: 70$ ) produced via hydrolysis of a $\mathrm{WCl}_{6}$ and $\mathrm{Sn}$ (II)ethyl-hexanoate solution prior to calcination at $550^{\circ} \mathrm{C}$ for $2 \mathrm{~h}$ under air-flow [2]. Nanostructured powders of the solid solutions of $\mathrm{Sn}$ and $\mathrm{Ti}$ mixed oxide were produced via symplectic gel coprecipitation of stoichiometric $\mathrm{Sn}(4+)$ and $\mathrm{Ti}(4+)$ hydroalcoholic solutions, after calcination of the resulting xerogel at $550^{\circ} \mathrm{C}$ for $2 \mathrm{~h}$ under air-flow. Solid solutions of $\mathrm{Ti}_{\mathrm{x}} \mathrm{Sn}_{1-\mathrm{x}} \mathrm{O}_{2}$ at two values of $x(x=0.3,0.9)$ will be hereinafter labeled as ST30 and ST90 [3-5]. 
The crystalline phase of the powders was investigated by Xray diffraction (XRD) (Philips $\mathrm{PW} 1820 / 00 \mathrm{Cu} \mathrm{K}$ radiation with $\lambda=1.54 \AA$ ) performed at room temperature.

The powders were used to screen-print sensing layers onto miniaturized alumina substrates. The obtained sensing layers were fired the for 1 $\mathrm{h}$ at temperatures in the range $650-850{ }^{\circ} \mathrm{C}$.

The gas measurements were performed with the flow-through technique in a sealed test chamber. Air and gases were supplied by certified bottles and humidity was provided by means of a bubbler filled with distilled water. The gases chosen for the application were ethyl-mercaptan, ammonia, hydrogen sulfide and n-butanol. The first three are primary gases responsible of malodors in decomposition products, whereas the last is a reference gas for the odorimetric intensity scale. Humidity was monitored through a $\mathrm{HIH}-3610$ Series Honeywell humidity sensor. We investigated on the responses of the sensors under dry $(\mathrm{RH}<$ $2 \%$ at $\left.25^{\circ} \mathrm{C}\right)$ and wet $\left(\mathrm{RH}=23 \%\right.$ at $\left.35^{\circ} \mathrm{C}\right)$ conditions. The response will be defined as the ratio between the conductance in gas and in air, $G_{\text {gas }} / G_{\text {air. }}$

\section{Results and discussion}

The response of the set of sensors was investigated vs. working temperature in order to determine the optimal detecting condition for ethy-mercaptan (Fig. 1), ammonia (Fig. 2), hydrogen sulfide (Fig. 3) and n-butanol (Fig. 4). The concentrations of the target gases were chosen in order to be comparable with the Recommended Exposure Limits (REL) by the $\mathrm{NIOSH}$ (United States National Institute for Occupational Safety and Health). Indeed, for ethyl-mercaptan we chose the REL concentration of $0.5 \mathrm{ppm}$, for ammonia $10 \mathrm{ppm}$ $(\mathrm{REL}=25 \mathrm{ppm})$, for hydrogen sulfide $2 \mathrm{ppm}$ $(\mathrm{REL}=10 \mathrm{ppm})$. For what concerns $\mathrm{n}$-butanol we chose a concentration of $5 \mathrm{ppm}$, which corresponds to a weak odor (about 12 OU Odor Units).

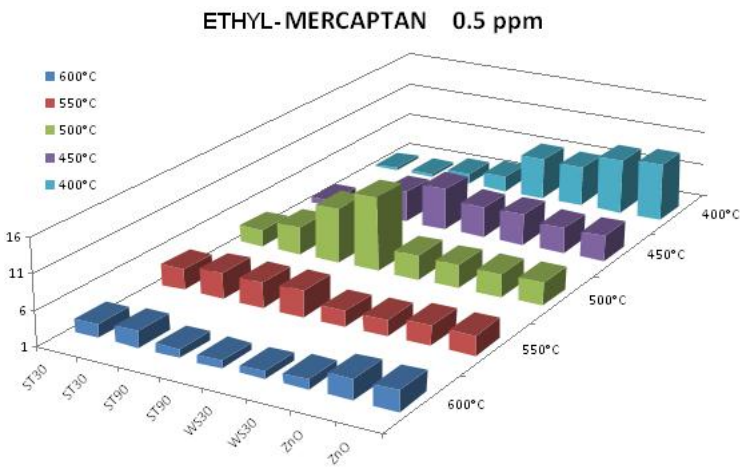

Fig. 1. Response of the set of sensors to $0.5 \mathrm{ppm}$ of ethyl-mercaptan vs. temperature in dry condition.

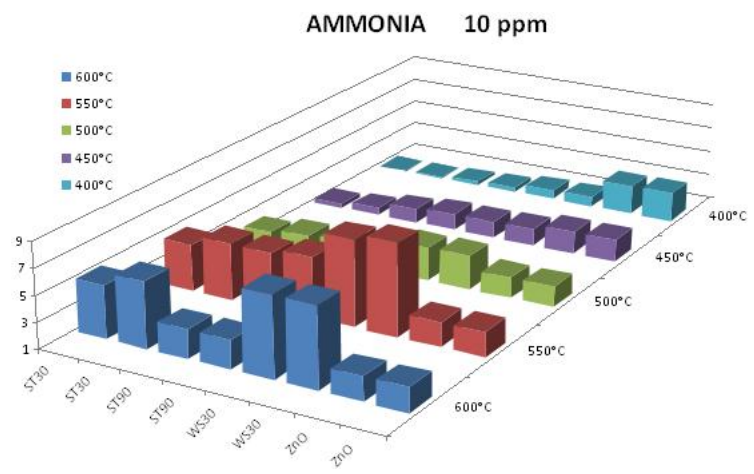

Fig. 2. Response of the set of sensors to $10 \mathrm{ppm}$ of ammonia vs. temperature in dry condition.

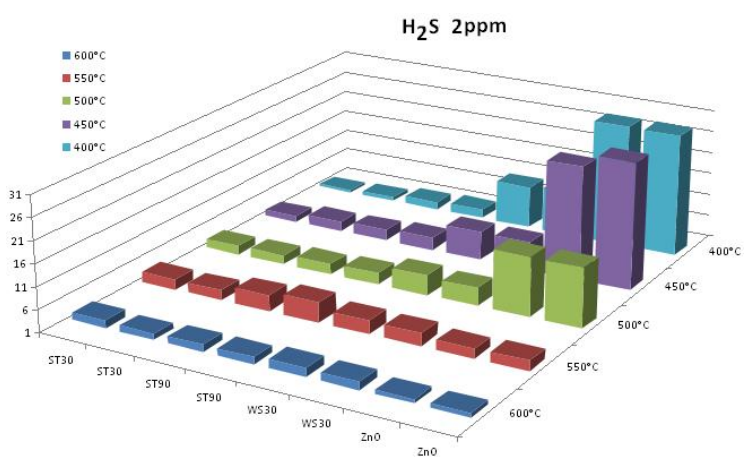

Fig. 3. Response of the set of sensors to $2 \mathrm{ppm}$ of hydrogen sulfide vs. temperature in dry condition.

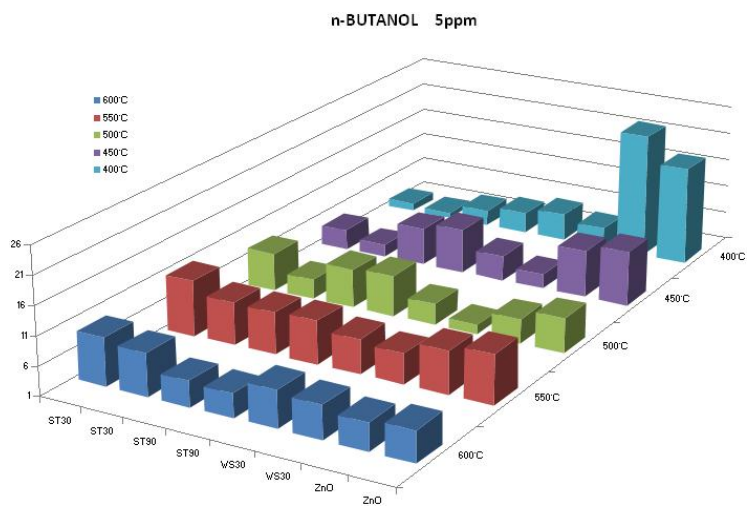

Fig. 4. Response of the set of sensors to $5 \mathrm{ppm}$ of $n$-butanol vs. temperature in dry condition.

The experimental results show diversification in the responses to the first three gases, while they are significant but more homogeneous in the case of $n$-butanol. This is an indication of suitability of this set of sensors both for the selective detection of the three target gases and for generic odor applications.

The optimal working temperature for each gas can be found in Tab. 1. At each best temperature for each gas we measured the response to various concentrations of interest, as can be seen in Figs. 5-8. 
Tab. 1: The optimal working temperature $T_{\text {best }}\left({ }^{\circ} \mathrm{C}\right)$ for all analyzed films.

\begin{tabular}{|c|c|c|c|c|}
\hline & $\begin{array}{c}\text { Ethyl- } \\
\text { merca } \\
\text { ptan } \\
0.5 \\
\mathrm{ppm}\end{array}$ & $\begin{array}{c}\mathrm{H}_{2} \mathrm{~S} 2 \\
\mathrm{ppm}\end{array}$ & $\begin{array}{c}\mathrm{NH}_{3} \\
10 \\
\mathrm{ppm}\end{array}$ & $\begin{array}{c}\mathrm{n}- \\
\text { butano } \\
\mathrm{I}\end{array}$ \\
\hline ST30 & 500 & 550 & 600 & 550 \\
\hline ST90 & 500 & 550 & 550 & 550 \\
\hline WS30 & 400 & 400 & 550 & 600 \\
\hline ZnO & 400 & 400 & 400 & 400 \\
\hline
\end{tabular}

The sensors can be arranged in an array capable to sensitively detect the target gases. Indeed, ST30 only can sensitively detect ammonia. ST90 detects both $\mathrm{H}_{2} \mathrm{~S}$ and ammonia, thus if coupled with an ST30 it can sensitively detect $\mathrm{H}_{2} \mathrm{~S}$. $\mathrm{ZnO}$ detects both Ethylmercaptan and $\mathrm{H}_{2} \mathrm{~S}$, thus, if added to the two above-mentioned sensors, can sensitively detect Ethyl-mercaptan. An array of three sensors would be sufficient to the goal, excluding WS30 from the array, since, for this particular application, is the less selective of the investigated materials. The sensitivity of ST90, defined as the derivative of the response vs. the gas concentration, strongly increases after 0.2 ppm of $\mathrm{H}_{2} \mathrm{~S}$. This is a useful feature since health risks becomes significant at such concentrations. For the other sensors vs. the other gases, the response is always quite high to concentrations below the exposure limits.

\section{ETHYL-MERCAPTAN @ Tbest}

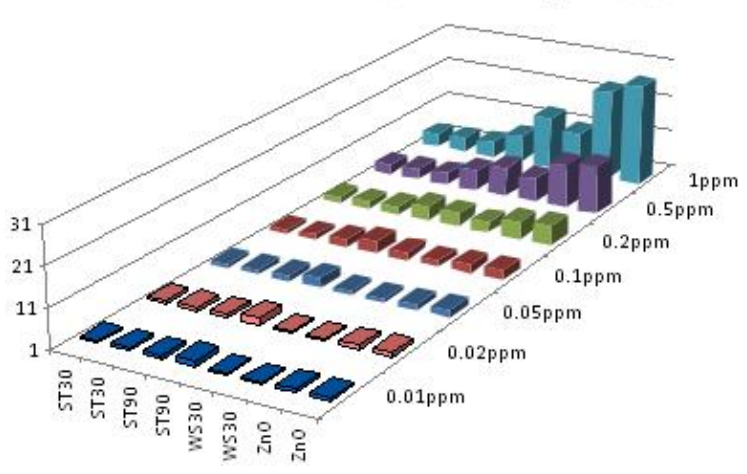

Fig. 5. Responses vs. ethyl-mercaptan within 0.01 and 1 ppm under dry condition.

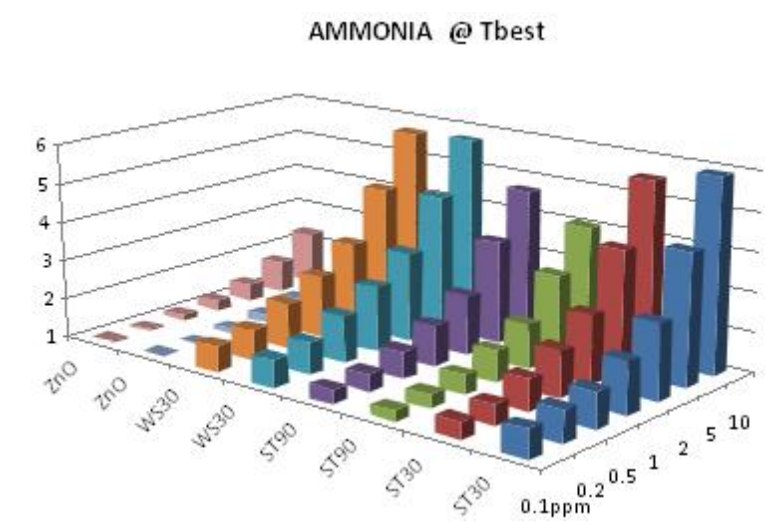

Fig. 6. Responses vs. ammonia within 0.1 and 10 ppm under dry condition.

$$
\mathrm{H}_{2} \mathrm{~S} @ \text { Tbest }
$$

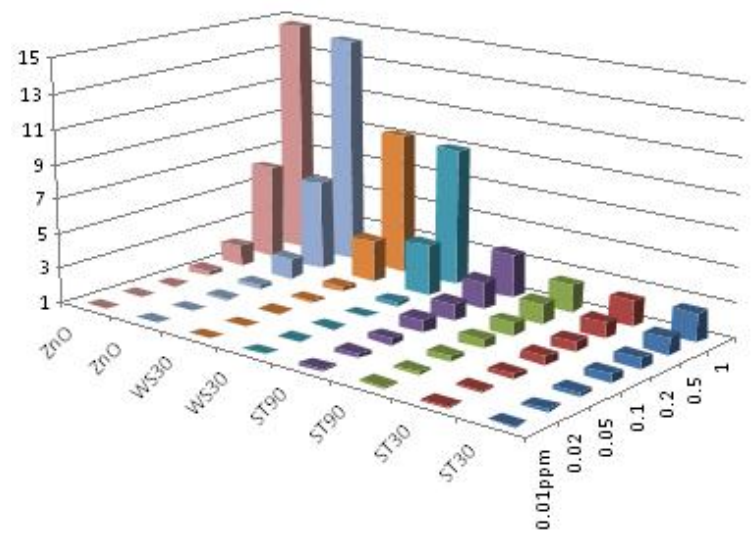

Fig. 7. Responses vs. $\mathrm{H}_{2} \mathrm{~S}$ within 0.01 and 1 ppm under dry condition.

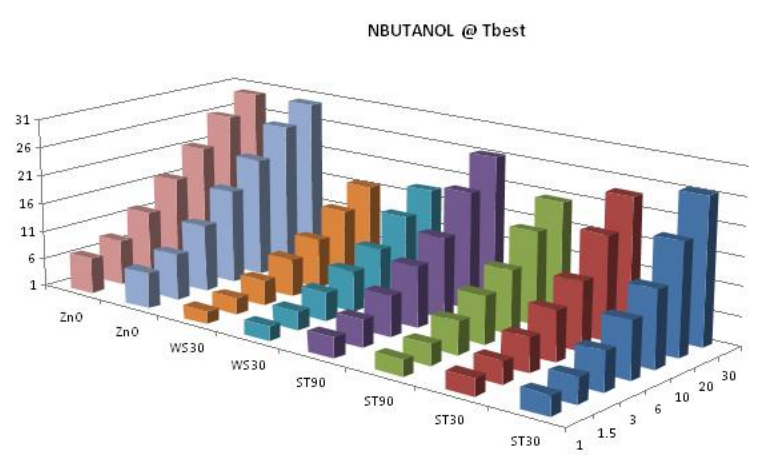

Fig. 8. Responses vs. n-butanol within 1 and 30 ppm under dry condition.

The response of the sensors was tested vs. the highest concentration of each gas under wet condition $\left(\mathrm{RH}=23 \%\right.$ at $\left.35^{\circ} \mathrm{C}\right)$. The significant decrease in the response does not invalidate the capability of detection of the target gases (Fig. 9). 


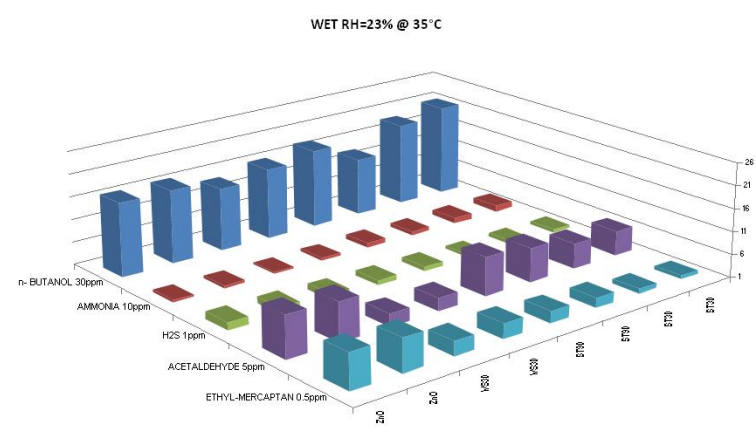

Fig. 9. Responses to $0.5 \mathrm{ppm}$ of ethyl-mercaptan, $30 \mathrm{ppm}$ of $n$-butanol, $10 \mathrm{ppm}$ of ammonia, $5 \mathrm{ppm}$ of acetaldehyde, and $1 \mathrm{ppm}$ of $\mathrm{H}_{2} \mathrm{~S}$ under wet condition.

\section{Conclusions}

The problem of sensing harmful gas pollutants and malodors typical of decomposition of organic substances has been addressed via chemoresistive gas sensors. A set of four sensing materials $(\mathrm{ZnO}$, two mixed solutions of $\mathrm{Sn}$ and $\mathrm{Ti}$ oxides and a mixed solution of $\mathrm{W}$ and Sn oxides) has been tested in dry and wet conditions. It resulted that, with a proper choice of the working temperatures, an array of three sensors can sensitively detect the target gases, quantifying both the health risk and the odor intensity.

\section{Acknowledgements}

This work was supported by Programma Operativo FESR 2007-2013, Regione EmiliaRomagna - Attività I.1.1. B. Fabbri acknowledges financial support by Spinner Regione Emila-Romagna.

\section{References}

[1] M.C. Carotta, A. Cervi, V. di Natale, S. Gherardi, A. Giberti, V. Guidi, D. Puzziovio, B. Vendemiati, G. Martinelli, M. Sacerdoti, D. Calestani, A. Zappettini, M. Zha, L. Zanotti, Sensors and Actuators B 137, 164-169 (2009); doi:10.1016/j.snb.2008.11.007

[2] M.C Carotta, A. Fioravanti, S. Gherardi, A. Giberti, B. Vendemiati, G. Martinelli, Proc. Electrochemical Society Meeting 216, 181 (2009)

[3] M.C. Carotta, S. gherardi, V. Guidi, C. Malagù, G. Martinelli, B. Vendemiati, M. Sacerdoti, G. Ghiotti, S. Morandi, A. Bismuto, P. Maddalena, A. Setaro, Sensors and Actuators B 130, 38-45 (2008); doi:10.1016/j.snb.2007.07.112

[4] M.C. Carotta, A. Cervi, A. Giberti, V. Guidi, C. Malagù, G. Martinelli, D. Puzzovio, Sensors and Actuators B 133, 516-520 (2008); doi:10.1016/j.snb.2008.03.012

[5] M.C. Carotta, A. Cervi, A. Giberti, V. Guidi, C. Malagù, G. Martinelli, D. Puzziovio, Sensors and Actuators B 136, 405-409 (2009); doi:10.1016/j.snb.2008.12.052 